\title{
Endoscopic endonasal resection of epidermoid cysts involving the ventral cranial base
}

\author{
Jonathan A. Forbes, MD, ${ }^{1}$ Matei Banu, MD, ${ }^{2}$ Kurt Lehner, BS, ${ }^{3}$ Malte Ottenhausen, MD, MBA, ${ }^{1}$ \\ Emanuele La Corte, MD, ${ }^{4}$ Andrew F. Alalade, MBBS, FRCS(SN), ${ }^{5}$ Edgar G. Ordóñez-Rubiano, MD, ${ }^{1,6}$ \\ Jeffrey P. Greenfield, MD, ${ }^{1}$ Vijay K. Anand, MD, ${ }^{7}$ and Theodore H. Schwartz, MD ${ }^{1,7,8}$
}

\begin{abstract}
'Department of Neurological Surgery, Weill Cornell Medical College, NewYork-Presbyterian Hospital, New York, New York; 2Department of Neurological Surgery, Columbia Medical College, NewYork-Presbyterian Hospital, New York, New York; ${ }^{3} \mathrm{H}$ ofstraNorthwell Health School of Medicine, New York, New York; ${ }^{4}$ University of Milan and Department of Neurosurgery, Foundation IRCCS Neurological Institute Carlo Besta, Milan, Italy; ${ }^{5}$ Victor Horsley Department of Neurosurgery, The National Hospital for Neurology and Neurosurgery, London, United Kingdom; ${ }^{6}$ Department of Neurological Surgery, Fundación Universitaria de Ciencias de la Salud (FUCS), Hospital de San José, Bogotá, Colombia; ${ }^{7}$ Department of Otolaryngology, Weill Cornell Medical College, NewYork-Presbyterian Hospital, New York, New York; and ${ }^{8}$ Department of Neuroscience, Weill Cornell Medical College, NewYork-Presbyterian Hospital, New York, New York
\end{abstract}

OBJECTIVE Epidermoid cysts (ECs) commonly extend to involve the ventral cisterns of the cranial base. When present, symptoms arise due to progressive mass effect on the brainstem and adjacent cranial nerves. Historically, a variety of open microsurgical approaches have been used for resection of ECs in this intricate region. In recent years, the endoscopic endonasal approach (EEA) has been proposed as an alternative corridor that avoids crossing the plane of the cranial nerves. To date, there is a paucity of data in the literature regarding the safety and efficacy of the EEA in the treatment of ECs of the ventral cranial base.

METHODS The authors reviewed a prospectively acquired database of EEAs for resection of ECs over 8 years at Weill Cornell, NewYork-Presbyterian Hospital. All procedures were performed by the senior authors. Standardized clinical and radiological parameters were assessed before and after surgery. Statistical tests were used to determine the impact of previous surgery and tumor volume on extent of resection and recurrence as well as the method of closure on rate of CSF leak.

RESULTS Between January 2009 and February 2017, 7 patients (4 males and 3 females; age range 16-70 years) underwent a total of 8 surgeries for EC resection utilizing the EEA. Transplanum and transclival extensions were performed in 3 and 5 patients, respectively. Methods of closure incorporated a gasket seal in 6 of 8 procedures and a nasoseptal flap in 7 of 8 procedures. Gross-total resection (GTR) was achieved in 43\% of patients, and near-total resection (> 95\%) was obtained in another $43 \%$. Complications included diabetes insipidus $(n=2)$, postoperative CSF leak $(n=2)$, transient third cranial nerve palsy $(n=1)$, and epistaxis $(n=1)$. With a mean follow-up of 43.5 months, recurrence has been observed in 2 of 7 patients. In 1 case, reoperation for recurrence was required 71 months following the initial surgery. Use of the gasket-seal technique with nasoseptal flap coverage significantly correlated with the absence of postoperative CSF leakage $(p=0.018)$. GTR was achieved in $25 \%$ of the patients who had prior surgeries and in $50 \%$ of patients without previous resections. The mean volume of cysts in which GTR was achieved $\left(4.3 \pm 1.8 \mathrm{~cm}^{3}\right)$ was smaller than that in which subtotal or near-total resection was achieved (12.2 $\left.\pm 11 \mathrm{~cm}^{3}, p=0.134\right)$.

CONCLUSIONS The EEA for resection of ECs of the ventral cranial base is a safe and effective operative strategy that avoids crossing the plane of the cranial nerves. In the authors' experience, gasket-seal closure with nasoseptal flap coverage has been associated with a decreased risk of postoperative CSF leakage.

https://thejns.org/doi/abs/10.3171/2017.12.JNS172575

KEYWORDS endonasal; endoscopic; transsphenoidal, transclival; epidermoid; skull base; suprasellar; intrasellar; ventral; transplanum

ABBREVIATIONS CN = cranial nerve; CPA = cerebellopontine angle; DWI = diffusion-weighted imaging; EC = epidermoid cyst; EEA = endoscopic endonasal approach; EOR = extent of resection; GTR = gross-total resection; WCMC = Weill Cornell Medical College.

SUBMITTED October 13, 2017. ACCEPTED December 19, 2017.

INCLUDE WHEN CITING Published online June 8, 2018; DOI: 10.3171/2017.12.JNS172575. 
$\mathrm{E}$ PIDERMOID cysts (ECs) have been estimated to account for approximately $1 \%$ of intracranial spaceoccupying lesions. ${ }^{36}$ They are hypothesized to arise from incorporation of epidermal elements during the processes of neural groove closure and disjunction of surface ectoderm, which occur between the 3rd and 5th weeks of gestation. ${ }^{9}$ Importantly, ECs are not inherently neoplastic, although malignant degeneration has been reported. ${ }^{2,41}$ Their growth is linear and, in most cases, occurs as a result of progressive accumulation of desquamated epithelial cells and related cellular debris. ${ }^{21}$ ECs most commonly originate in the cisterns of the cerebellopontine angle (CPA) and parasellar region. ${ }^{43}$ Symptoms of ECs of the cranial base arise secondary to progressive mass effect on the brainstem and adjacent cranial nerves, although presentation with aseptic meningitis due to cyst rupture has also been described. ${ }^{2,8}$ Surgery is indicated in cases of neurological symptoms secondary to mass effect or cyst rupture and is sometimes considered in asymptomatic patients in whom interval growth has been demonstrated.

To date, the safety and efficacy of open, microsurgical resection of these lesions has been demonstrated in numerous large series. ${ }^{1,15,43}$ However, open surgical access to the site of origin of these tumors often involves microdissection through narrow spaces between involved cranial nerves. Moreover, it is common for ECs of the cranial base to intimately involve multiple cranial nerves and vascular structures-sometimes with dense adherence. Direct visualization, especially of ventral midline pathology, can be limited in many instances by interposition of the brainstem, cerebellum, and cranial nerves. Collectively, these characteristics limit the ability to achieve gross-total resection (GTR) in many cases, even following highly invasive approaches. ${ }^{1,10}$

In contrast to traditional open microsurgical approaches to the cranial base, the endoscopic endonasal approach (EEA) offers a direct, minimally invasive route that allows for a marked reduction in the need for brain retraction. ${ }^{12,13,29}$ Direct visualization of regions of adherence in the ventral cisterns is often afforded. The benefits of the EEA to access various alternative pathologies of the ventral cranial base have been well described. ${ }^{3,33,34}$ While isolated case reports and small case series exist that describe the utility of these approaches in the resection of ECs of the cranial base, ${ }^{11,17,19,35}$ there is an overall paucity of information in the literature regarding this surgical option, especially regarding ventral ECs of the posterior fossa. Thus, we sought to describe the clinical presentation and surgical outcomes of 7 consecutive patients with ventral ECs of the cranial base treated using the EEA.

\section{Methods}

\section{Preoperative Data Collection}

After receiving institutional review board approval from Weill Cornell Medical College (WCMC), we compiled de-identified data of patients who underwent EEAs for resection of cranial base epidermoid cysts over a period of 8 years from 2009 to 2017. Prior to surgery, all patients underwent CT of the head and MRI of the brain with and without contrast enhancement. Preoperative access to diffusion- weighted imaging (DWI) was not universally available. All patients also underwent routine preoperative endocrine testing. In patients who reported visual abnormalities or had radiological evidence suspicious for possible optic nerve or chiasmal impingement, preoperative neuro-ophthalmological evaluation was performed. The electronic medical records were examined for relevant preoperative data (e.g., age, sex, history of previous surgeries, presenting symptoms, and neurological deficits). Preoperative MRI was used to assess tumor size and extent of cisternal involvement. Cyst volume was estimated using measurements obtained from MRI utilizing the ellipsoid formula $(\mathrm{A} \times \mathrm{B} \times \mathrm{C} / 2)$.

\section{Surgical Technique}

The surgical team for patients in this series consisted of an endoscopic skull base neurosurgeon (T.H.S.) and an otorhinolaryngologist (V.K.A.). Prior to surgery, the specific operative technique for the EEA is planned based on the extent of cisternal involvement. Preoperatively, an antibiotic regimen that includes vancomycin and a thirdgeneration cephalosporin is administered within 1 hour of incision. Ten milligrams of dexamethasone and $50 \mathrm{mg}$ of diphenhydramine are administered prior to the anticipated instillation of intrathecal fluorescein. After lumbar drain insertion, intrathecal fluorescein is given per protocol to help with visualization of intraoperative CSF leakage during tumor removal and again following closure. The safety and utility of this practice has been reported in previous publications. ${ }^{4,37,40,48}$ The patient is positioned supine with the head immobilized in Mayfield clamp 3-point fixation. Neuronavigation with MRI is used to assist with planning of bony removal and intraoperative localization. The nasopharynx is approached using a binostril approach, and nasoseptal flap harvest is performed prior to posterior septectomy. The remainder of the procedure is tailored based on the known anatomical extension of the epidermoid cyst. Some element of a transsphenoidal approach is utilized in all patients, often involving partial or complete removal of the sella. In select patients, transplanum and/or transclival extensions are incorporated into the operative approach. The routine surgical techniques used to provide exposure for these extensions have been previously described. ${ }^{27,45}$

Intraoperatively, every attempt is made to achieve an extracapsular GTR. In patients noted to have dense adherence of the tumor capsule to vital neurovascular structures, portions of adherent capsule are left and surgical goals transition to attempted resection of all safely accessible cyst material. Following resection of the EC, the method of closure has evolved with time and now routinely involves the gasket-seal technique followed by nasoseptal flap coverage. The technique for gasket-seal closure has been previously described..$^{20,28}$ Postoperatively, lumbar drainage is used to remove $5 \mathrm{ml}$ of CSF per hour for 24-72 hours. Patients are routinely placed on a 10-day dexamethasone taper following surgery. The CSF is not routinely examined prior to lumbar drain discontinuation unless clinically indicated.

\section{Intra- and Postoperative Data Collection}

Relevant intra- and postoperative data (e.g., surgical ap- 
TABLE 1. Preoperative clinical characteristics of patients who underwent endoscopic endonasal resection of an EC

\begin{tabular}{|c|c|c|c|c|c|c|}
\hline Case No. & Age (yrs), Sex & Preop Symptoms & Preop Deficit & Previous Op & Tumor Vol $\left(\mathrm{cm}^{3}\right)$ & Cisterns Involved* \\
\hline 1 & $26, \mathrm{M}$ & $\mathrm{HA}$ & None & None & 3.1 & PP, PM \\
\hline \multirow[t]{2}{*}{2} & $27, \mathrm{M}$ & HA, dizziness & None & None & 14.1 & SS, IP, CC, PP \\
\hline & $33 \dagger$ & Visual deterioration & None & EEA & 1.7 & SS, PP, CPA cistern \\
\hline 3 & $70, F$ & None & None & FTC $\times 2$, VPS & 3.4 & SS, IP \\
\hline 4 & $19, \mathrm{~F}$ & Visual deterioration & Lt CN II & None & 6.4 & SS, IP, CC \\
\hline 5 & $31, \mathrm{~F}$ & Gait instability, TN, double vision & Lt CNs VII \& VIII & TLA, VPS, VAS & 31.0 & IP, PP, CC, CPA cistern, PM \\
\hline 6 & $16, \mathrm{M}$ & $\mathrm{HA}$ & None & None & 7.7 & PP, IP, CC \\
\hline 7 & $65, M$ & Double vision & CN VI & RSA & 6.5 & PP \\
\hline
\end{tabular}

$\mathrm{CC}=$ crural cistern; FTC = frontotemporal craniotomy; $\mathrm{HA}=$ headache; $\mathrm{IP}=$ interpeduncular; $\mathrm{PM}=$ premedullary; $\mathrm{PP}=$ prepontine; $\mathrm{RSA}=$ retrosigmoid approach; $\mathrm{SS}$ = suprasellar; TLA = translabyrinthine approach; $\mathrm{TN}=$ trigeminal neuralgia; VAS = ventriculoatrial shunt; VPS = ventriculoperitoneal shunt.

* Boldface type indicates the dominant cistern involved.

† Patient underwent reoperation EEA for resection following growth of suprasellar component of tumor with associated subjective visual decline.

proach, intraoperative complications, method of closure, postoperative neurological deficit, postoperative complications, improvement in symptoms following surgery, and radiological and clinical follow-up) were assessed after surgery. The extent of cyst resection was assessed intraoperatively via visual inspection by the senior authors and postoperatively using MRI imaging. Any element of residual cyst material documented in the operative note or on postoperative imaging precluded the designation of a GTR. Every patient underwent a full neurological examination on a daily basis after surgery, at the time of discharge, and during follow-up in the outpatient setting. The postoperative endocrine status of each patient was monitored, when indicated, during the patient's hospital stay and electively in the outpatient setting. Patients with visual symptoms underwent postoperative neuro-ophthalmological examination. Cyst recurrence was monitored with MRI every 6 months during the 1st postoperative year followed by 1- or 2-year intervals.

\section{Statistical Analysis}

IBM SPSS (version 23 for Macintosh, IBM Corp.) was used for the statistical analysis. Fisher's exact test was used to assess whether patients with a history of previous resection were significantly less likely to achieve a GTR via EEA than patients with no history of previous surgery. Fisher's exact test was also used to assess whether method of closure (gasket seal and nasoseptal flap, nasoseptal flap alone, or neither adjunct) was significantly associated with postoperative CSF leakage. The independent t-test was used to assess the relationship between tumor volume and extent of resection (EOR) as well as tumor recurrence.

\section{Results}

During the period of time from 2009 to 2017,7 patients (4 males and 3 females) underwent a total of 8 surgeries for cyst resection utilizing the EEA. At the time of surgery, the ages of the patients ranged from 16 to 70 years. No patient had preoperative endocrine abnormalities. Additional preoperative clinical and radiological characteristics can be found in Table 1 . Of the 2 patients with preoperative visual deterioration, the patient in case 2 suffered from subjective blurry vision and the other patient (case 4) had monocular blindness. EC size, based on preoperative MRI results, ranged from 1.7 to $31 \mathrm{~cm}^{3}$. The dominant cistern involved was the prepontine in 3 procedures, the suprasellar in 3 procedures, and the crural in 2 procedures. Three of the patients had a history of epidermoid recurrence following previous microsurgical approaches at outside hospitals. Of this group, 2 patients had required CSF diversion following initial craniotomy. The remaining 4 patients underwent primary resection via EEA. One of the 4 patients who underwent primary resection via EEA developed a recurrence that manifested in visual symptoms and required a subsequent EEA for resection 6 years later.

Lumbar drains were placed preoperatively in 6 of 8 surgeries to deliver intrathecal fluorescein and/or allow for CSF diversion in the early postoperative period to minimize the risk of postoperative CSF leakage. In 2 patients, placement of a lumbar drain prior to surgery was not performed; in one of these patients, a lumbar drain was unable to be placed prior to surgery and required placement under fluoroscopic guidance immediately following surgery. In another patient, who had a history of a ventriculoperitoneal shunt, the decision was made to forego lumbar drain insertion. Intraoperatively, a high-flow CSF leak occurred in all procedures. The transsphenoidal corridor for access to the sphenoid sinus was used in all patients. In 3 patients with significant suprasellar involvement, a transplanum extension was incorporated as well. ECs in the interpeduncular, prepontine, or premedullary cisterns were accessed via an additional transclival extension in 5 patients. This approach was used to access tumor extension to the CPA in 2 patients and crural cistern in 3 patients. A pituitary transposition was used in 1 patient. Following resection of the EC, the methods of closure varied. In 1 patient (case 1, the first EEA procedure performed for $\mathrm{EC}$ resection at our institution), fat graft buttressed with vomer and DuraSeal (Covidien) was used for closure, but a nasoseptal flap was not utilized. In all remaining patients, a nasoseptal flap was used; in 6 of 7 of these surgeries, a gasket-seal closure was utilized in addition to the nasoseptal flap. In the remaining patient (case 2), a button closure was utilized and buttressed with a nasoseptal flap. In all but one procedure, intraoperative estimated blood loss was less than $50 \mathrm{ml}$. 
TABLE 2. Intraoperative and postoperative clinical characteristics of patients who underwent endoscopic endonasal resection of an EC

\begin{tabular}{|c|c|c|c|c|c|c|c|}
\hline Case No. & Approach & Method of Closure & EOR & Clinical Improvement & Complications & $\mathrm{FU}$ (mos) & Cyst Recurrence \\
\hline 1 & $\mathrm{TC}$ & Fat graft & GTR & Yes & CSF leak & 102 & No \\
\hline & TS, TP, TC & Fat graft + GS + NSF & NTR (98\%) & Yes & Transient DI & 78 & Yes \\
\hline 2 & TS, TC & $\mathrm{FL}+\mathrm{NSF}$ & $\operatorname{STR}(80 \%)^{*}$ & Yes & $\begin{array}{l}\text { DI requiring desmopressin, } \\
\text { epistaxis, CSF leak }\end{array}$ & 7 & No \\
\hline 3 & TS, TP & GS + NSF & GTR & NA & None & 50 & Yes \\
\hline 4 & TS, TP & GS + NSF & GTR & No & None & 17 & No \\
\hline 5 & TS, TC & GS + NSF & NTR (98\%) & Yes & None & 42 & No \\
\hline 6 & TC w/ PT & GS + NSF & NTR (98\%) & Yes & Transient DI, transient CN III palsy & 4 & No \\
\hline 7 & $\mathrm{TC}$ & GS + NSF & NTR (95\%) & No & None & 48 & No \\
\hline
\end{tabular}

$\mathrm{DI}=$ diabetes insipidus; FL = fascia lata; FU = follow-up; GS = gasket seal; NA = not available; NSF = nasoseptal flap; PT = pituitary transposition; STR = subtotal resection; $\mathrm{TC}=$ transclival; $\mathrm{TP}=$ transplanum; $\mathrm{TS}=$ transsphenoidal.

* GTR of the suprasellar component or residual EC was achieved.

Following surgery, the duration of lumbar drainage lasted 1 to 3 days. Drainage was maintained at $5 \mathrm{ml} / \mathrm{hr}$ until removal. In the majority of patients, the lumbar drain was removed on postoperative day 2. Postoperative MRI was performed within 72 hours following surgery and used to grade EOR. GTR, as assessed intraoperatively and with postoperative MRI, was achieved in 3 of 7 patients (43\%). Near-total resection (NTR), which was defined as resection of $>95 \%$ of the cyst, was obtained in another $43 \%$ (3 of the 4 remaining patients). In cases of near- or subtotal resection, residual cyst was left because of dense adherence to vital adjacent neurovascular structures. GTR was attained in one-third of patients with a history of previous craniotomy for resection and was not attained in the $1 \mathrm{pa}-$ tient with a history of prior EEA for resection. Altogether, GTR was attained in 1 of $4(25 \%)$ reoperations and 2 of 4 (50\%) first-time operations. The difference in the ability to achieve GTR in patients with and without a prior history of surgery did not reach statistical significance. Cyst volume impacted EOR as a trend. The mean volume of cysts in which GTR was achieved $\left(4.3 \pm 1.8 \mathrm{~cm}^{3}\right)$ was smaller than that in which STR or NTR was achieved $(12.2 \pm 11$ $\mathrm{cm}^{3} ; \mathrm{p}=0.134$ ). Additional relevant intra- and postoperative patient variables can be found in Table 2 .

Postoperative follow-up ranged from 4 to 102 months (mean 43.5 months). Of the 6 patients who experienced various symptoms prior to surgery, 4 patients have noted significant clinical improvement following EEA. One patient (case 4, discussed below) presented with monocular blindness that did not improve following GTR. Another patient (case 7), who had a history of prior craniotomy for resection of an EC, presented with a cranial nerve $(\mathrm{CN}) \mathrm{VI}$ palsy that did not improve following EEA for re-resection. Postoperative complications can be found in Table 2. Two patients experienced postoperative CSF leakage. Interestingly, both postoperative CSF leaks were encountered in procedures in which a gasket-seal closure was not utilized. No CSF leaks were encountered in the 6 surgeries that utilized a gasket seal for closure. Both episodes of CSF leakage required return to the operating room for revision of closure and lumbar drain placement. One patient (case 1) healed successfully with gasket-seal repair and lumbar drainage alone. After the patient in case 2 experienced a CSF leak following EEA re-resection, gasket-seal closure with nasoseptal flap coverage and associated lumbar drainage resulted in successful repair. Patients who were closed with the gasket-seal technique with nasoseptal flap coverage were significantly less likely to develop postoperative CSF leakage $(p=0.018)$. The choice of surgical corridor did not significantly correlate with CSF leak risk.

Two patients (cases 2 and 6) had transient postoperative diabetes insipidus. After reoperation, the patient in case 2 developed permanent diabetes insipidus. Regarding neurological complications, the other patient (case 6) noted a transient left $\mathrm{CN}$ III palsy that resolved approximately 3 months after surgery. No patient had a new, permanent neurological deficit. There was 1 case of delayed epistaxis 3 weeks following the revision closure that resolved with conservative measures. The choice of surgical corridor or EOR did not correlate with the risk of postoperative complications.

Radiological evidence of cyst recurrence was observed in 2 of 7 patients at a mean interval of 41 months after surgery. In one of these patients (case 2), recurrence detected at 56 months postoperatively was observed until 71 months postoperatively, at which point the patient underwent EEA reoperation for subjective visual symptoms. Slight regrowth of the EC was noted in the other patient (case 3) approximately 2 years after surgery. This cyst recurrence has since remained stable after initial detection, and the patient remains clinically asymptomatic.

\section{Illustrative Cases Case 4}

A 19-year-old right-handed woman presented with a 10-month history of marked, progressive visual deterioration in the left eye. By the time of presentation, vision in the left eye had deteriorated to the point of monocular blindness, confirmed with preoperative visual field assessment. MRI of the brain demonstrated a nonenhancing lesion in the suprasellar region with homogeneous restricted diffusion, indicative of an EC (Fig. 1A). Given the progressive and severe nature of the visual loss, surgery was scheduled in an urgent manner.

In the operating room, a lumbar drain was placed, and 

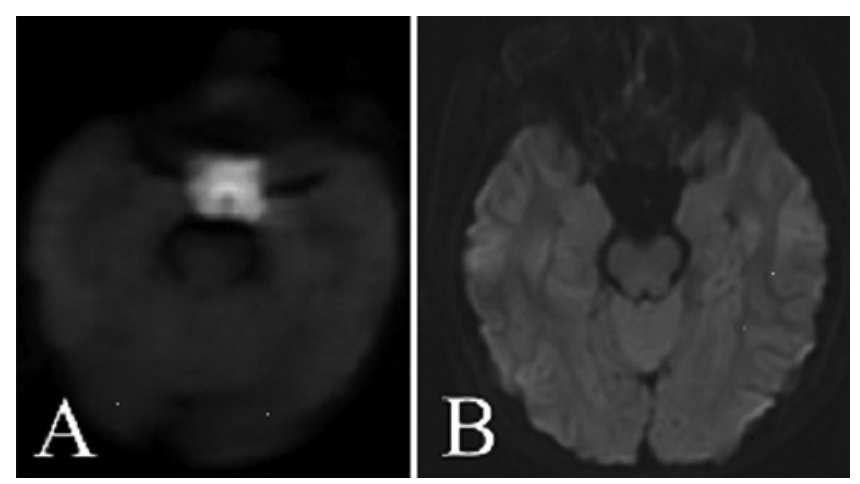

FIG. 1. Case 4. A: Preoperative axial DWI scan of the brain, demonstrating a DWI-hyperintense lesion involving the suprasellar region. B: Axial DWI scan obtained in the immediate postoperative period demonstrating GTR of the previously visualized epidermoid cyst.

intrathecal fluorescein was given. The patient was placed in pins and registered to neuronavigation. A nasoseptal flap was harvested, and a posterior ethmoidectomy and wide sphenoidotomy were performed. The upper aspect of the sella, tuberculum, and planum sphenoidale were removed using a drill and Kerrison instrumentation. The dura was opened using a sickle knife. The EC was internally decompressed (Fig. 2A) prior to meticulous extracapsular dissection (Fig. 2B). The cyst capsule was carefully removed off of the anterior communicating artery complex (Fig. 2C). Full decompression of the thinned left optic nerve was achieved (Fig. 2D). Following resection, a $45^{\circ}$ scope was inserted and used to verify GTR. Fascia lata was subsequently harvested from the left thigh and used to reconstruct the skull base defect with rigid Medpor (Stryker) using the gasket-seal technique. The gasket seal was covered with a nasoseptal flap and DuraSeal. An edited and narrated compilation of the operative steps utilized in this procedure can be found in Video 1.

VIDEO 1. Case 4. Edited and narrated intraoperative video demonstrating endonasal resection of a suprasellar EC. Acomm = anterior communicating artery. Copyright Weill Cornell Medical Center.

Published with permission. Click here to view.

Clinically, the left monocular blindness did not recover after surgery. Postoperative MRI (Fig. 1B) confirmed GTR of the EC. Repeat MRI performed approximately 17 months after surgery continued to demonstrate no evidence of residual EC. The patient was noted to be clinically stable at this time.

\section{Case 5}

A 31-year-old right-handed woman initially presented to an outside facility with left facial weakness and decreased hearing on the left in 2003. Subsequent MRI revealed an $\mathrm{EC}$ in the prepontine cistern with extension to the bilateral (left $>$ right) CPAs. The lesion continued to enlarge, and the patient underwent a left translabyrinthine approach for subtotal resection at an outside facility in October 2012. This procedure sacrificed residual hearing on the left and was complicated by postoperative CSF leakage that subsequently manifested with bacterial meningitis. The patient required a return to the operating room for wound revision and repair of CSF leak in November 2012 and subsequent

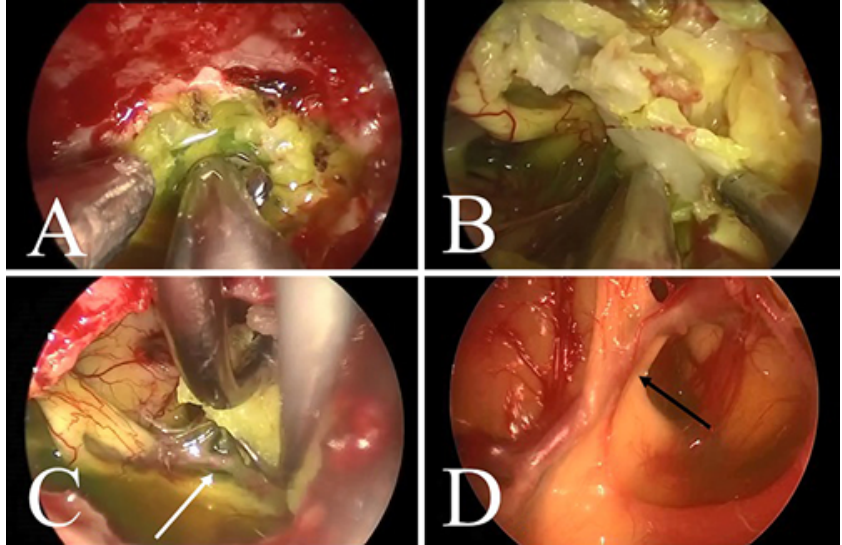

FIG. 2. Case 4. Intraoperative images. A: After opening of the dura, the EC could be immediately visualized and was internally decompressed. B: After internal debulking, the cyst capsule could be dissected off adjacent neurovascular structures. C: Additional extracapsular dissection was necessary to remove cyst material off of the anterior communicating artery complex (arrow). D: After GTR, the thinned left optic nerve (arrow) could be visualized. Figure is available in color online only.

ventriculoperitoneal shunt placement in December 2012 that was later converted to a ventriculoatrial shunt.

The patient presented to WCMC in 2014 with progressive gait ataxia, right trigeminal neuralgia, intermittent double vision, and headaches. On examination, she had no hearing on the left and exhibited slight left facial weakness and gait ataxia. MRI revealed a $4.2 \times 4.1 \times 3.6-\mathrm{cm}$ T2 hyperintense lesion encasing the basilar artery, extending into the bilateral (right $>$ left) CPAs, and resulting in significant mass effect on the midbrain, pons, and right brachium pontis (Fig. 3A).

The decision was made to proceed with an EEA for resection. After placing a lumbar drain, a nasoseptal flap was harvested, and a wide sphenoidotomy and partial ethmoidectomy were performed. The clivus was subsequently drilled from the bottom of the sella to the approximate rostrocaudal location of the vertebrobasilar junction. Following dural opening, portions of the EC were removed off of the surface of the brainstem and basilar artery. The cyst material was followed rostrally, where it was noted to envelop $\mathrm{CN} \mathrm{V}$ on the right. A $45^{\circ}$ endoscope and angled suction were used at this stage to maximize the lateral EOR in the CPA. A small amount of cyst material lateral to $\mathrm{CN} V$ was left. Additionally, a small amount of residual capsule and EC noted to be densely adherent to the basilar artery was likewise not resected. After all safely accessible portions of the epidermoid cyst had been removed, autologous fascia lata was harvested and used to perform a gasket-seal closure with Medpor as a rigid buttress. The gasket seal was subsequently covered with a nasoseptal flap.

Clinically, the patient noted improvement in her gait, right trigeminal neuralgia, and double vision following surgery. Postoperative MRI (Fig. 3B and C) demonstrated resection of the vast majority (98\%) of the epidermoid cyst with reexpansion of the brainstem. Since the initial MRI, repeat studies have remained stable without interval growth of the small amount of residual cyst, now 42 months postoperatively. She continues to have minimal 

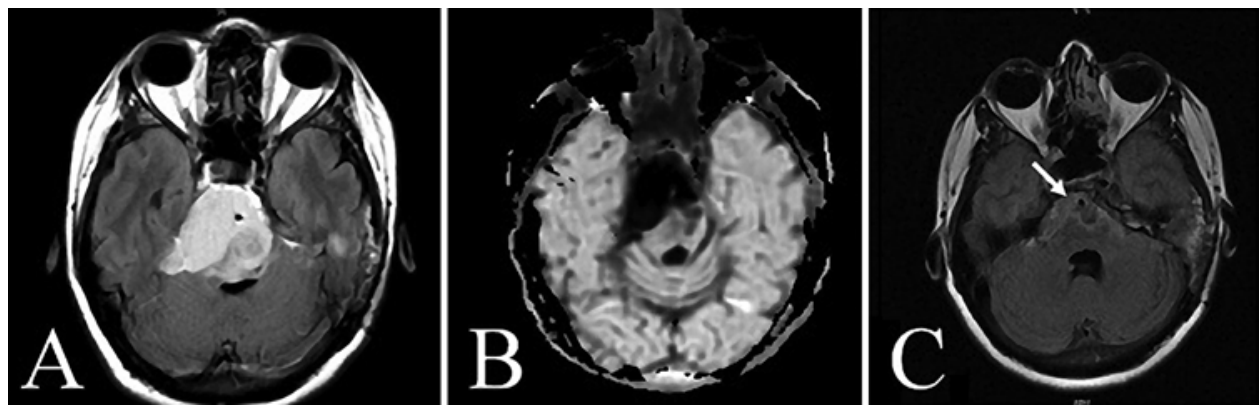

FIG. 3. Case 5. A: Preoperative axial MRI scan of the brain (FLAIR sequence) demonstrating a hyperintense lesion causing severe impingement of the pons with extension into the right CPA (no preoperative DWI sequence was available for review). B: Axial DWI scan obtained in the immediate postoperative period, demonstrating NTR of the previously visualized epidermoid cyst. C: Axial FLAIR image obtained approximately 3 months after surgery, revealing marked reduction in mass effect on the brainstem following NTR with reexpansion of the fourth ventricle. A small amount of material with intermediate T2 signal adherent to the basilar artery suspicious for residual cyst is present (arrow).

symptoms referable to the trigeminal neuralgia on a regimen of carbamazepine.

\section{Case 6}

A 16-year-old right-handed boy initially presented to an outside facility in 2014 with headaches. No neurological deficits were present on examination. CT demonstrated a hypodensity in the left prepontine and crural cisterns. Signal characteristics on subsequent MRI were consistent with EC. The decision was initially made to manage the lesion conservatively. After repeat MRI in 2016 demonstrated evidence of interval enlargement (Fig. 4A) with new associated edema in the pons and midbrain, the family elected to proceed with resection.

In the operating room, a lumbar drain was attempted, but the catheter could not be passed following attainment of CSF. As a result, no intrathecal fluorescein was given. Bilateral nasoseptal flaps were harvested, and a wide sphenoidotomy was performed. Transsellar and transclival extensions were utilized to expose the sellar and clival dura (Fig. 5A) as well as the left cavernous sinus. An interdural pituitary hemi-transposition was then performed to allow for removal of the posterior clinoid on the left side. Doppler ultrasound was used to identify the basilar artery prior to dural opening. The EC could be immediately visualized. The cyst capsule was opened with angled microscissors (Fig. 5B). The EC was subsequently internally decompressed (Fig. 5C) prior to microdissection of the capsule off adjacent neural and vascular structures. In particular, the cyst was noted to be densely adherent to the lateral aspect of the left CN III. Consequently, a small amount of residual cyst was left. After the remainder of the EC had been removed, autologous fascia lata was harvested and used to perform a gasket-seal closure with Medpor as a rigid buttress (Fig. 5D). The gasket seal was subsequently covered with a nasoseptal flap. A lumbar drain was successfully placed using fluoroscopic guidance immediately following surgery.

In the immediate postoperative period, the patient experienced transient diabetes insipidus in addition to a left $\mathrm{CN}$ III palsy. Postoperative MRI demonstrated a small amount of residual EC lateral to the left CN III, as expected (Fig. 4B). At clinical reevaluation 3 months after surgery, his endocrinological function had normalized, and the left $\mathrm{CN}$ III palsy had resolved. At time of most recent follow-up, the patient reported marked improvement in the headaches he had experienced prior to surgery.

\section{Discussion}

\section{Traditional Microsurgical Approaches}

It has long been known that complete removal of the EC capsule, which is composed of stratified squamous epithelium, is the only way to ensure true prevention of tumor recurrence. ${ }^{7}$ However, the capsule is sometimes noted to be densely adherent to adjacent neural and vascular structures, a phenomenon that may be more common during reoperation for resection of these lesions. ${ }^{1}$ The desire to achieve a complete resection to minimize the incidence of EC recurrence is tempered by the increased risk that is sometimes associated with extracapsular resection. For this reason, many authors have advocated against aggressive resection of the cyst capsule in some ${ }^{5}$ or all ${ }^{51}$ procedures.

While ECs share a proclivity for the cranial base, the size and location of individual lesions vary considerably. The CPA is the most frequent site of origin, but the suprasellar/parasellar region, middle fossa, and prepontine cistern are common alternative locations. ${ }^{1,43}$ The nomenclature chosen to characterize numerous historical series reflects this complex anatomical origin. Methods of anatomical categorization in large historical series have included the CPA, ${ }^{15,24,30,32,43,44,51}$ posterior fossa, ${ }^{5,42,46}$ fourth ventricle ${ }^{18,49}$ and pineal region. ${ }^{14}$ To achieve maximal safe resection of the EC and capsule, the neurosurgeon must be facile with a number of different approaches, with selection depending on the individual characteristics of the tumor. In a recent review of 38 surgical procedures performed by Aboud et al., 9 different surgical approaches were utilized: the transmastoid retrosigmoid approach in $32 \%$, the combined petrosal approach in $21 \%$, the posterior petrosal in 16\%, the orbitozygomatic approach in 13\%, and 5 other procedures in the remaining $18 \%$ of procedures performed. ${ }^{1}$ The majority of cases in this series involved the CPA, although extension to the prepontine cistern was common.

In the subcategory of ECs that arise in the posterior 


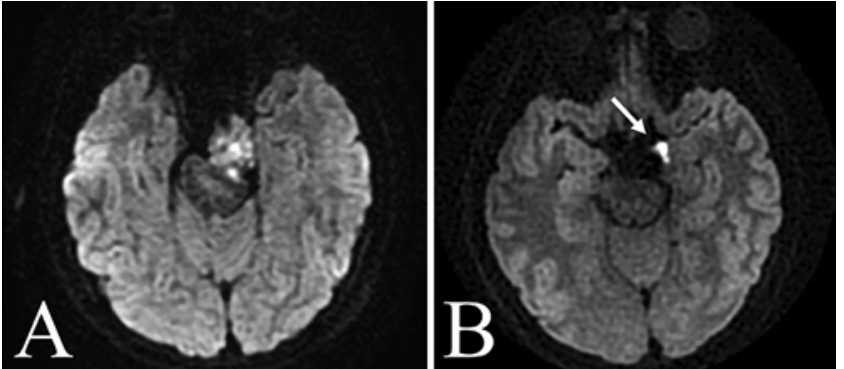

FIG. 4. Case 6. A: Preoperative axial DWI scan of the brain, demonstrating a hyperintense lesion resulting in partial impingement of the left pons. B: Axial DWI scan obtained in the immediate postoperative period, demonstrating NTR of the previously visualized epidermoid cyst with full decompression of the brainstem. A small amount of hyperintense residual cyst material lateral to the course of $\mathrm{CN}$ III is present (arrow).

fossa, Yaşargil et al. reported that a large CPA component creates an artificial surgical channel during resection that permits surgical access to ventral extension via a retromastoid approach. ${ }^{54}$ However, other authors have cautioned that even in the case of a large CPA component, surgical access to contralateral cisterns ventral to the brainstem can be limited. ${ }^{47}$ This problem is often magnified in cases in which the component of the EC in the CPA is small or nonexistent. A handful of series have systematically evaluated the application of various surgical strategies in patients with ventral ECs of the posterior fossa. ${ }^{25,47}$ Shimamoto et al. recommended use of the anterior transpetrosal approach for prepontine ECs, citing the direct visualization of associated neurovascular structures that is afforded and the ease by which EC extension into Meckel's cave can be addressed. ${ }^{47}$ They described limitations that included an inability to access cyst material inferior to the level of the internal auditory meatus in the setting of intact hearing and an increased risk of CSF leakage when compared to more traditional approaches. ${ }^{47}$ Other authors have reported increased risk of injury to the facial nerve, cochlea, and ipsilateral temporal lobe with this exposure. ${ }^{22,53}$ To avoid the approach-related morbidity and narrow corridor associated with the anterior transpetrosal approach, the use of endoscope-assisted microsurgical resection has been advocated as a method to improve visualization, decrease neural retraction, and maximize EOR in this setting. These techniques have been reported in patients with ventral ECs of the posterior fossa as well as the suprasellar region. ${ }^{16,25,52,55}$ While the endoscope-assisted technique permits improved visualization of "blind spots" associated with standard exposures, methods of surgical dissection can be unwieldly and attainment of hemostasis, on occasion, suboptimal.

In contrast to the techniques described above, reports utilizing the endonasal corridor as a means of resecting ECs ventral to the brainstem are uncommon. In 2005, Esposito et al. described their experience with endonasal primary microscopic resection of 2 large prepontine ECs. ${ }^{17}$ In this study, subtotal resection was achieved in both patients without new postoperative neurological or endocrinological deficit. However, 1 patient had a postoperative CSF leak that required 2 additional reoperations and a trial of lumbar drainage to repair. Long-term follow-up for recurrence beyond 12 months was not available. The authors reported
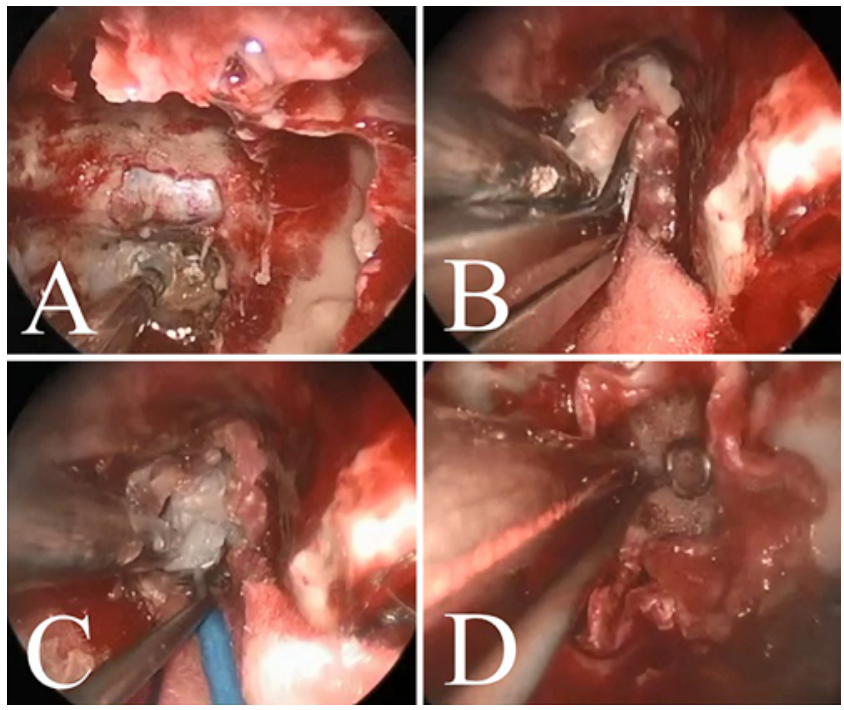

FIG. 5. Case 6. Intraoperative photographs. A: Sellar dura is visible. The drill is used to remove the rostral bone of the clivus. B: Following opening of the dura, the cyst capsule is incised using angled microscissors. C: Internal decompression of the EC is performed to facilitate subsequent extracapsular dissection. D: Following NTR, the defect is reconstructed using the gasket-seal technique. Figure is available in color online only.

limitations that included a restricted exposure ipsilateral to the nostril of choice and concern regarding the inability to achieve proximal vascular control in the event of injury. It should be noted that the surgical exposure in this study involved use of a nasal speculum and that a nasoseptal flap was not used in closure. A subsequent report by McCoul et al. in 2012, that included cases 1 and 2 from this series, described the early results following EEA for resection of keratinaceous cysts involving the ventral cranial base at our institution. ${ }^{31}$ Of the 3 patients in this series, one of whom harbored a dermoid cyst, GTR was achieved in $2(67 \%)$. Both epidermoid cysts were located ventral to the brainstem. One patient (case 1) experienced a postoperative CSF leak that was successfully repaired using the gasket-seal technique. While additional reports have described endonasal approaches for prepontine neurenteric cysts, ${ }^{39}$ in recent years very little has been reported on the topic of EEA for the resection of ECs ventral to the brainstem. To date, no long-term follow-up in this cohort has been reported.

In contrast to reports of ventral ECs of the posterior fossa, studies describing endonasal management of intra- and/ or suprasellar ECs have been comparatively more common. ${ }^{6,50}$ In 2013, Costa et al. reported the first use of EEAs in resection of an EC involving the intra- and suprasellar regions. ${ }^{11}$ The patient's vision improved considerably after this procedure; however, GTR was not achieved. In 2017, Nakassa et al. published a report describing successful resection of an epidermoid cyst involving the pituitary stalk using a combined infra- and suprasellar approach-again with postoperative improvement in vision. ${ }^{35}$ These reports are consonant with other studies that have described excellent visual outcomes after endonasal approaches for various pathologies in this region. ${ }^{3,34}$ To date, the only case series dedicated to this topic was provided by Formichev et 
TABLE 3. Previous studies that have reported expanded endonasal endoscopic approaches for resection of ventral EC of the cranial base in the literature

\begin{tabular}{|c|c|c|c|c|c|c|c|c|}
\hline Authors \& Year* & $\begin{array}{l}\text { No. of } \\
\text { Pts }\end{array}$ & Location of EC & $\begin{array}{c}\text { No. of GTRs } \\
\text { Achieved }\end{array}$ & $\begin{array}{l}\text { Mean } \\
\text { EOR }\end{array}$ & $\begin{array}{c}\text { Postop } \\
\text { CSF Leak }\end{array}$ & $\begin{array}{l}\text { NPP Cranial } \\
\text { Neuropathy }\end{array}$ & $\begin{array}{l}\text { NPP Pituitary } \\
\text { Insufficiency }\end{array}$ & $\begin{array}{c}\text { Mean FU } \\
\text { (mos) }\end{array}$ \\
\hline Esposito et al., 2005 & 2 & PP, PM, IP, CPA, CC & $0(0 \%)$ & $77 \%$ & 1 & $0(0 \%)$ & $0(0 \%)$ & 12 \\
\hline Costa et al., 2013 & 1 & SS, IS & $0(0 \%)$ & NS & 0 & $0(0 \%)$ & $0(0 \%)$ & 12 \\
\hline Fomichev et al., 2016 & 6 & NSt & $5(83 \%) \ddagger$ & NS & 1 & $0(0 \%)$ & $1(17 \%)$ & 42 \\
\hline Nakassa et al., 2018 & 1 & SS, IS & $1(100 \%)$ & $100 \%$ & 0 & $0(0 \%)$ & $0(0 \%) \S$ & 12 \\
\hline Current study & 7 & PP, PM, SS, IS, IP, CPA, CC & $3(43 \%)$ & $96 \%$ & 2 & $0(0 \%)$ & $1(14 \%)$ & 43.5 \\
\hline
\end{tabular}

IS = intrasellar; NPP = new permanent postoperative; NS = not specified; pts = patients.

* In the study by Esposito et al., the microscope was used for primary visualization with accessory visualization provided by the endoscope. In all other studies, a primary EEA was utilized.

$\dagger$ The authors reported that all 6 epidermoid cysts were in the chiasmatic region.

¥ The authors reported "radical removal" of the epidermoid mass in 5 of 6 cases, but stated that it was necessary to leave fragments of the capsule in all patients.

$\S$ One year after surgery, the patient was diagnosed with new primary hypothyroidism and started on a regimen of levothyroxine therapy.

al., who reported radiological GTR in 5 of 6 patients with chiasmatic-region ECs with no recurrences noted during a mean follow-up of 42 months. ${ }^{19}$ Complications in this series included postoperative CSF leak in 1 patient, meningitis in 2 patients, and new anterior pituitary insufficiency in 1 patient. Aside from the series by Fomichev et al., no long-term data on the topic of EEA for resection of ECs in the suprasellar region are available. A summary of previous reports describing EEA for resection of all rostrocaudal locations of ventral cranial base ECs is presented in Table 3.

\section{Role of the EEA}

While EEAs have become an important alternative to traditional open microsurgical techniques for cranial base pathology in recent years, a proper understanding of the associated anatomical limitations is imperative. In the suprasellar region, extension lateral to the optic nerves and/ or carotid bifurcation can complicate attempts at GTR. ${ }^{26}$ Cyst extension to the middle fossa does not preclude EEA, as long as the lesion in question has an anteromedial surface presentation.$^{38}$ In the posterior fossa, significant lateral petrous extension represents a relative contraindication to EEA when GTR is desired ${ }^{33}$ In every patient with an EC, the pros and cons of endonasal approaches must be weighed against traditional open microsurgical alternatives.

While the low incidence and inherent heterogeneity of ECs complicate attempts at systematic analysis, comparison to historical landmark studies remains a necessary component of validation. Previous open microsurgical series in patients with ECs have reported postoperative cranial neuropathy in $10 \%-33 \%$ of patients following rates of GTR that have varied from $0 \%$ to $75 \%$.,10,30,43,46,49,51 The incidence of a permanent postoperative neurological deficit $(0 \%)$ and ability to achieve GTR $(43 \%)$ in this series compare favorably in this regard. A slow rate of growth, difficulty assessing radiological progression, and/or limited follow-up can make it challenging to provide accurate estimates of EC recurrence. Cyst recurrence in the aforementioned series was reported in $0 \%-33 \%$ of patients, detected during a mean follow-up that ranged from 3.25 to 14.5 years. ${ }^{1,10,30,43,46,49,51}$ The prevalence of cyst recurrence $(28.6 \%)$ in this series appears comparable to that of histori- cal standards, although the mean follow-up of 43.5 months is among the shorter intervals that has been reported.

Postoperative CSF fistula occurred following 2 of 8 procedures in this study (25\%). The frequency of this complication is higher than what has commonly been reported in the majority of open microsurgical series. As an example, in the most recent large series by Aboud et al., 5 postoperative CSF leaks were noted in 34 patients (15\%). Interestingly, while there are few surgical case series that have exclusively evaluated prepontine ECs, the study by Shimamoto et al. reported a postoperative CSF fistula in $33 \%$ of patients. ${ }^{47}$ Given the considerable evolution in endonasal closure techniques that has occurred since the first procedure performed in this analysis, it is important to interpret the aforementioned figures in the proper context. The initial patient in this series underwent surgery prior to universal adoption of the nasoseptal flap, which has subsequently been shown to result in a marked decrease in the incidence of postoperative CSF leakage following endonasal approaches. ${ }^{23}$ In the 7 surgeries that followed the initial surgery in which nasoseptal flaps were utilized, only 1 patient experienced a postoperative CSF leak (14.3\%). Moreover, the senior authors at our institution now routinely utilize the gasket-seal closure in cases of expanded endonasal approaches, ${ }^{20,28}$ which was associated with a significant decrease in the rate of postoperative CSF fistulas in this study. It is likely that, with progressive advances in operative technique and surgical instrumentation, this risk of CSF leakage after EEA will continue to decrease with time.

\section{Conclusions}

The EEA for resection of ventral ECs of the cranial base should be considered a viable option in the armamentarium of neurosurgeons who routinely treat this pathology. This approach is particularly useful for ECs located medial to the cranial nerve envelope, as transgression of this plane is avoided. To our knowledge, this study represents the largest series of patients with ECs treated via the EEA and is the first study in the literature to present long-term (> 1 year) follow-up data on EC ventral to the brainstem resected via the EEA. 


\section{References}

1. Aboud E, Abolfotoh M, Pravdenkova S, Gokoglu A, Gokden M, Al-Mefty O: Giant intracranial epidermoids: is total removal feasible? J Neurosurg 122:743-756, 2015

2. Abramson RC, Morawetz RB, Schlitt M: Multiple complications from an intracranial epidermoid cyst: case report and literature review. Neurosurgery 24:574-578, 1989

3. Bander ED, Singh H, Ogilvie CB, Cusic RC, Pisapia DJ, Tsiouris AJ, et al: Endoscopic endonasal versus transcranial approach to tuberculum sellae and planum sphenoidale meningiomas in a similar cohort of patients. J Neurosurg 128:40-48, 2018

4. Banu MA, Kim JH, Shin BJ, Woodworth GF, Anand VK, Schwartz TH: Low-dose intrathecal fluorescein and etiologybased graft choice in endoscopic endonasal closure of CSF leaks. Clin Neurol Neurosurg 116:28-34, 2014

5. Berger MS, Wilson CB: Epidermoid cysts of the posterior fossa. J Neurosurg 62:214-219, 1985

6. Boggan JE, Davis RL, Zorman G, Wilson CB: Intrasellar epidermoid cyst. Case report. J Neurosurg 58:411-415, 1983

7. Bucy PC: Intradiploic epidermoid (cholesteatoma) of the skull. Arch Surg 31:190-199, 1935

8. Cantu RC, Ojemann RG: Glucosteroid treatment of keratin meningitis following removal of a fourth ventricle epidermoid tumour. J Neurol Neurosurg Psychiatry 31:73-75, 1968

9. Choremis C, Economos D, Gargoulas A, Papadatos C: Intraspinal epidermoid tumours (cholesteatomas) in patients treated for tuberculous meningitis. Lancet 271:437-439, 1956

10. Chowdhury FH, Haque MR, Sarker MH: Intracranial epidermoid tumor; microneurosurgical management: an experience of 23 cases. Asian J Neurosurg 8:21-28, 2013

11. Costa F, Fornari M, Felisati G, Maccari A, Bauer D, Lasio G: Epidermoid cyst of the pituitary stalk: case report and review of the literature. Neurosurg Q 23:108-111, 2013

12. de Divitiis E, Cappabianca P, Cavallo LM: Endoscopic transsphenoidal approach: adaptability of the procedure to different sellar lesions. Neurosurgery 51:699-707, 2002

13. de Divitiis O, Conti A, Angileri FF, Cardali S, La Torre D, Tschabitscher M: Endoscopic transoral-transclival approach to the brainstem and surrounding cisternal space: anatomic study. Neurosurgery 54:125-130, 2004

14. Desai KI, Nadkarni TD, Fattepurkar SC, Goel AH: Pineal epidermoid cysts: a study of 24 cases. Surg Neurol 65:124129,2006

15. deSouza CE, deSouza R, da Costa S, Sperling N, Yoon TH, Abdelhamid MM, et al: Cerebellopontine angle epidermoid cysts: a report on 30 cases. J Neurol Neurosurg Psychiatry 52:986-990, 1989

16. Ebner FH, Roser F, Thaher F, Schittenhelm J, Tatagiba M: Balancing the shortcomings of microscope and endoscope: endoscope-assisted technique in microsurgical removal of recurrent epidermoid cysts in the posterior fossa. Minim Invasive Neurosurg 53:218-222, 2010

17. Esposito F, Becker DP, Villablanca JP, Kelly DF: Endonasal transsphenoidal transclival removal of prepontine epidermoid tumors. Neurosurgery 56 (2 Suppl):E443, 2005

18. Fiume D, Gazzeri G, Spallone A, Santucci N: Epidermoid cysts of the fourth ventricle. Surg Neurol 29:178-182, 1988

19. Fomichev D, Kalinin P, Kutin M, Sharipov O: Endoscopic endonasal surgery of epidermoid cysts of the chiasmatic region. World Neurosurg 96:159-164, 2016

20. Garcia-Navarro V, Anand VK, Schwartz TH: Gasket seal closure for extended endonasal endoscopic skull base surgery: efficacy in a large case series. World Neurosurg 80:563-568, 2013

21. Guidetti B, Gagliardi FM: Epidermoid and dermoid cysts. Clinical evaluation and late surgical results. J Neurosurg 47:12-18, 1977
22. Hitselberger WE, Horn KL, Hankinson H, Brackmann DE, House WF: The middle fossa transpetrous approach for petroclival meningiomas. Skull Base Surg 3:130-135, 1993

23. Kassam AB, Thomas A, Carrau RL, Snyderman CH, Vescan A, Prevedello D, et al: Endoscopic reconstruction of the cranial base using a pedicled nasoseptal flap. Neurosurgery 63 (1 Suppl 1):ONS44-ONS53, 2008

24. Kobata H, Kondo A, Iwasaki K: Cerebellopontine angle epidermoids presenting with cranial nerve hyperactive dysfunction: pathogenesis and long-term surgical results in 30 patients. Neurosurgery 50:276-286, 2002

25. Krass J, Hahn Y, Karami K, Babu S, Pieper DR: Endoscopic assisted resection of prepontine epidermoid cysts. J Neurol Surg A Cent Eur Neurosurg 75:120-125, 2014

26. Kulwin C, Schwartz TH, Cohen-Gadol AA: Endoscopic extended transsphenoidal resection of tuberculum sellae meningiomas: nuances of neurosurgical technique. Neurosurg Focus 35(6):E6, 2013

27. Laufer I, Anand VK, Schwartz TH: Endoscopic, endonasal extended transsphenoidal, transplanum transtuberculum approach for resection of suprasellar lesions. J Neurosurg 106:400-406, 2007

28. Leng LZ, Brown S, Anand VK, Schwartz TH: "Gasket-seal" watertight closure in minimal-access endoscopic cranial base surgery. Neurosurgery 62 (5 Suppl 2):E342-E343, 2008

29. Liu JK, Decker D, Schaefer SD, Moscatello AL, Orlandi RR, Weiss $\mathrm{MH}$, et al: Zones of approach for craniofacial resection: minimizing facial incisions for resection of anterior cranial base and paranasal sinus tumors. Neurosurgery 53:1126-1137, 2003

30. Lunardi P, Missori P, Innocenzi G, Gagliardi FM, Fortuna A: Long-term results of surgical treatment of cerebello-pontine angle epidermoids. Acta Neurochir (Wien) 103:105-108, 1990

31. McCoul ED, Chow S, Lee DL, Anand VK, Schwartz TH: Endoscopic endonasal approach for resection of ventral skull base keratinaceous cysts. Int Form Allergy Rhinol 2:258263, 2012

32. Mohanty A, Venkatrama SK, Rao BR, Chandramouli BA, Jayakumar PN, Das BS: Experience with cerebellopontine angle epidermoids. Neurosurgery 40:24-30, 1997

33. Moussazadeh N, Kulwin C, Anand VK, Ting JY, Gamss C, Iorgulescu JB, et al: Endoscopic endonasal resection of skull base chondrosarcomas: technique and early results. J Neurosurg 122:735-742, 2015

34. Moussazadeh N, Prabhu V, Bander ED, Cusic RC, Tsiouris AJ, Anand VK, et al: Endoscopic endonasal versus open transcranial resection of craniopharyngiomas: a casematched single-institution analysis. Neurosurg Focus 41(6):E7, 2016

35. Nakassa AC, Chabot JD, Snyderman CH, Wang EW, Gardner PA, Fernandez-Miranda JC: Complete endoscopic resection of a pituitary stalk epidermoid cyst using a combined infrasellar interpituitary and suprasellar endonasal approach: case report. J Neurosurg 128:437-443, 2018

36. Obrador S, Lopez-Zafra JJ: Clinical features of the epidermoids of the basal cisterns of the brain. J Neurol Neurosurg Psychiatry 32:450-454, 1969

37. Placantonakis DG, Tabaee A, Anand VK, Hiltzik D, Schwartz TH: Safety of low-dose intrathecal fluorescein in endoscopic cranial base surgery. Neurosurgery 61 (3 Suppl):161-166, 2007

38. Prevedello DM, Ditzel Filho LF, Solari D, Carrau RL, Kassam AB: Expanded endonasal approaches to middle cranial fossa and posterior fossa tumors. Neurosurg Clin N Am 21:621-635, vi, 2010

39. Prevedello DM, Fernandez-Miranda JC, Gardner P, Madhok R, Sigounas D, Snyderman CH, et al: The transclival endoscopic endonasal approach (EEA) for prepontine neu- 
roenteric cysts: report of two cases. Acta Neurochir (Wien) 152:1223-1229, 2010

40. Raza SM, Banu MA, Donaldson A, Patel KS, Anand VK, Schwartz TH: Sensitivity and specificity of intrathecal fluorescein and white light excitation for detecting intraoperative cerebrospinal fluid leak in endoscopic skull base surgery: a prospective study. J Neurosurg 124:621-626, 2016

41. Russell DS, Rubinstein L: Pathology of Tumors of the Central Nervous System. London: Butler \& Tanner, 1989, pp 693-695

42. Sabin HI, Bordi LT, Symon L: Epidermoid cysts and cholesterol granulomas centered on the posterior fossa: twenty years of diagnosis and management. Neurosurgery 21:798 805, 1987

43. Samii M, Tatagiba M, Piquer J, Carvalho GA: Surgical treatment of epidermoid cysts of the cerebellopontine angle. J Neurosurg 84:14-19, 1996

44. Schroeder HW, Oertel J, Gaab MR: Endoscope-assisted microsurgical resection of epidermoid tumors of the cerebellopontine angle. J Neurosurg 101:227-232, 2004

45. Schwartz TH, Fraser JF, Brown S, Tabaee A, Kacker A, Anand VK: Endoscopic cranial base surgery: classification of operative approaches. Neurosurgery 62:991-1005, 2008

46. Talacchi A, Sala F, Alessandrini F, Turazzi S, Bricolo A: Assessment and surgical management of posterior fossa epidermoid tumors: report of 28 cases. Neurosurgery 42:242-252, 1998

47. Shimamoto Y, Kawase T, Sasaki H, Shiobara R, Yamada F: Anterior transpetrosal approach to the prepontine epidermoids. Skull Base Surg 9:75-80, 1999

48. Tabaee A, Placantonakis DG, Schwartz TH, Anand VK: Intrathecal fluorescein in endoscopic skull base surgery. Otolaryngol Head Neck Surg 137:316-320, 2007

49. Tancredi A, Fiume D, Gazzeri G: Epidermoid cysts of the fourth ventricle: very long follow up in 9 cases and review of the literature. Acta Neurochir (Wien) 145:905-911, 2003

50. Tuna H, Torun F, Torun ANI, Erdogan A: Intrasellar epidermoid cyst presenting as pituitary apoplexy. J Clin Neurosci 15:1154-1156, 2008

51. Vinchon M, Pertuzon B, Lejeune JP, Assaker R, Pruvo JP,
Christiaens JL: Intradural epidermoid cysts of the cerebellopontine angle: diagnosis and surgery. Neurosurgery 36:5257, 1995

52. Watanabe T, Ito E, Sato T, Ichikawa M, Oda K, Ando H, et al: Combined microsurgical and endoscopic removal of extensive suprasellar and prepontine epidermoid tumors. Neurol Med Chir (Tokyo) 51:684-688, 2011

53. Xiao X, Zhang L, Wu Z, Zhang J, Jia G, Tang J, et al: Surgical resection of large and giant petroclival meningiomas via a modified anterior transpetrous approach. Neurosurg Rev 36:587-594, 2013

54. Yaşargil MG, Abernathey CD, Sarioglu AÇ: Microneurosurgical treatment of intracranial dermoid and epidermoid tumors. Neurosurgery 24:561-567, 1989

55. Zhang Y, Wang C, Liu P, Gao X: Clinical application of neuroendoscopic techniques. Stereotact Funct Neurosurg 75:133-141, 2000

\section{Disclosures}

Drs. Anand and Schwartz: consultants for Elliquence and direct stock ownership in VisionSense.

\section{Author Contributions}

Conception and design: Schwartz, Forbes. Acquisition of data: Schwartz, Forbes. Drafting the article: Schwartz, Forbes. Critically revising the article: Schwartz, Forbes. Reviewed submitted version of manuscript: all authors. Approved the final version of the manuscript on behalf of all authors: Schwartz.

\section{Supplemental Information \\ Videos \\ Video 1. https://vimeo.com/254298764.}

\section{Correspondence}

Theodore H. Schwartz: Weill Cornell Medical College, New York,NY.schwarh@med.cornell.edu. 